\title{
As memórias póstumas de Guimarães Rosa: sobre a presença da obra rosiana na Polônia
}

\author{
GABRIEL BorowSKI ${ }^{1}$
}

Resumo: 0 presente artigo constitui o primeiro estudo sobre a presença da obra do autor brasileiro João Guimarães Rosa (1908-1967) na Polônia. O seu objetivo é identificar e analisar as referências à obra rosiana na imprensa polonesa e as resenhas críticas publicadas na Polônia, no período entre 1967 e 1977.

Palavras-Chaves: João Guimarães Rosa (19081967); tradução literária; recepção da literatura brasileira na Polônia; boom latino-americano.

\begin{abstract}
This paper is the first study of the presence of the works by the Brazilian author João Guimarães Rosa (1908-1967) in Poland. It aims to identify and analyze references to the works by Rosa in the Polish press and critical reviews published in Poland between 1967 and 1977.
\end{abstract}

Keywords: João Guimarães Rosa (1908-1967); literary translation; reception of the Brazilian literature in Poland; Latin-American boom.

1 Departamento de Estudos Portugueses e Tradução, Faculdade de Filologias, Universidade Jaguelônica de Cracóvia (Polônia). E-mail: gabriel.borowski@uj.edu.pl. 
«Nonada», ou seja, «nada, coisa sem importância» (Martins, 2008: 354-355) - é ao que se reduz, hoje, a presença da obra de João Guimarães Rosa (1908-1967) na Polônia. ${ }^{2}$ As referências contemporâneas ao autor oscilam entre afirmações da sua grandeza e provas do seu total esquecimento.

Por um lado, na enciclopédia da literatura mundial Literatura Świata, Rosa é considerado «[um] renovador da linguagem literária»³ que, com um «estilo original - ao mesmo tempo experimental e arcaizante [...], criou sua própria versão do realismo mágico» ${ }^{4}$, sendo «autor de um romance monumental e considerado obra-prima - Grande sertão: Veredas» (Kaczorowski, 2007: 300). Os respectivos verbetes na versão polonesa da Wikipédia também se referem ao autor como «frequentemente considerado o escritor brasileiro mais proeminente do século XX» (Wikipédia, s.d.) e a Grande sertão: Veredas como «um dos mais importantes romances latino-americanos, provavelmente o mais importante [romance] brasileiro» (Wikipédia, s.d.).

\footnotetext{
${ }^{2} \mathrm{O}$ presente artigo resulta das comunicações apresentadas no simpósio comemorativo dos 60 anos da publicação de Grande sertão: Veredas, realizado em novembro de 2016, na Universidade Eötvös Loránd, em Budapeste, e no simpósio comemorativo dos 50 anos da morte do autor realizado em janeiro de 2017, na Université Sorbonne Nouvelle - Paris 3.

${ }^{3}$ A tradução de todas as citações da língua polonesa para o português é da responsabilidade do autor do artigo.

${ }^{4}$ Rosa aparece também no verbete da Encyklopedia PWN dedicado ao realismo mágico, ao lado de Gabriel García Márquez, Miguel Ángel Asturias e Juan Rulfo, entre outros.
}

Por outro lado, as informações na Wikipédia contêm poucos dados biobibliográficos e não se comparam, por exemplo, com verbetes em inglês ou francês. No portal Lubimyczytac.pl o maior site de catalogação social na Polônia, equivalente nacional do Goodreads — , a obra de Rosa logrou apenas três comentários: um elogio (de uma aluna do curso de Estudos Portugueses, aliás) e duas críticas pouco favoráveis («o autor deve se ter esquecido que contar histórias à volta da fogueira não é o mesmo que as representar em um livro», alega um dos leitores).

Como é que se pode explicar, portanto, esta polarização na imagem do autor que, por um lado, costuma ser referido como um dos mais importantes escritores da América Latina, mas que ao mesmo tempo parece ter conseguido apenas uma presença efémera no sistema literário polonês? Por que motivo o autor não conseguiu um reconhecimento comparável, por exemplo, com o sucesso, provado pela quantidade de traduções e repercussões críticas, que teve na França (Faveri, 2009; Aguiar, 2011, 2014), na Alemanha e na Itália (Mendes, 2003), ou nos Estados Unidos (Armstrong, 2001)? Para responder a esta questão, no presente artigo pretendo me debruçar sobre as particularidades da introdução da obra rosiana na cultura polonesa e a sua recepção crítica na imprensa no período do chamado «boom latino-americano» (Gaszyńska-Magiera: 2011, 100-148), que em pleno período comunista da República Popular da Polônia atingiu 
dimensões inusitadas, já que no final do regime, em 1989, o número de traduções dos autores ibero-americanos na Polônia foi o segundo maior no mundo (Charchalis, 2012: 109-110). Todas as traduções das obras rosianas na Polônia foram publicadas na década de 1967 a 1977, ou seja, já depois da primeira onda de interesse internacional pela obra de Rosa (Rónai, 1965: 5).

Com este trabalho, procuro contribuir para a compreensão do problema da recepção da liã teratura brasileira na Polônia. Até o momento atual, a única publicação com uma visão mais panorâmica sobre esse tema é um ensaio de 11 páginas da autoria de Elżbieta Milewska (1992), incluído no pequeno volume bilíngue $L a$ presencia de la literatura latinoamericana en PoIonia/A presença da literatura latino-americana na Polônia. A questão aparece muitas vezes à margem de estudos sobre a circulação das literaturas ibero-americanas em geral (Gaszyńska-Magiera, 2011; Charchalis, 2012) ou acompanha trabalhos orientados para análise do próprio texto da tradução (Jeździkowski, 2010; Borowski, 2012, 2016, 2018). Por esta razão, no presente artigo, de índole necessariamente mais descritiva, apresento a primeira abordagem das referências na imprensa e das resenhas críticas das obras de João Guimarães Rosa publicadas na Polônia ${ }^{5}$ a fim de construir

${ }^{5}$ Os textos críticos foram identificados através da análise de todos os volumes da Polska Bibliografia Literacka (Bibliografia Literária da Polônia) concernentes aos anos uma narrativa capaz de explicar a razão da ausência atual do autor de Grande sertão: Veredas no sistema literário polonês.

\section{Uma vida póstuma}

O que se crê serem as primeiras referências ao autor em questão na Polônia são, talvez ironicamente, as notícias da sua morte. O falecimento de João Guimarães Rosa, ocorrido no dia 19 de novembro de 1967, é mencionado já no mês seguinte por dois periódicos poloneses. Na edição de 10 de dezembro de 1967 da Tygodnik Powszechny (Semanário Universal) - uma importante revista semanal focada nos assuntos sociais e culturais, lançada em 1945 —, publica-se a seguinte informação (contendo dados errados sobre a idade do escritor):

Faleceu no Brasil (em novembro) o proeminente ficcionista Guimaraes [sic] Rosa (57 [sic] anos), formado em Medicina. [...] É um poeta de mitos, alegorias, símbolos. o bem e o mal, o amor e o ódio são os temas principais de seus romances. Um excelente virtuose de linguagem. A crítica ocidental está encantada com seu estilo: a riqueza da palavra, a musicalidade da frase, a magia poética. (p. 4)

O pequeno texto faz um resumo da biografia e do percurso literário de Rosa, referindo obras como Magma, Sagarana, Grande sertão:

1944-1988 e da pesquisa na base de dados on-line que abrange o período subsequente, bem como da investigação própria em arquivos. 
Veredas e Corpo de baile (o último título escrito com gralha: Corpo de basle). Três semanas mais tarde, na edição de 31 de dezembro da revista mensal Nowe Książki (Novos Livros), dedicada às novidades literárias e ao mundo editorial em geral, aparece uma outra notícia (desta vez com a data equivocada), muito mais sucinta e aqui transcrita na íntegra:

No dia 22 [sic] de novembro de 1967 faleceu na idade de 59 anos o mais proeminente escritor brasileiro contemporâneo, Joaa [sic] Guimaraes [sic] Rosa. Rosa foi mencionado como candidato ao Prêmio Nobel e considerado - junto com Miguel Ángel Asturias, premiado com o Nobel neste ano - o representante mais notável não apenas da literatura brasileira, mas [da literatura] de toda a América Latina. (p. 1548)

Em ambos os comentários, baseados certamente em notícias sobre a morte do autor na imprensa ocidental, sobressai o fato de se tratar de um autor reconhecido pela crítica estrangeira, um escritor singular devido à elaboração da sua linguagem. Ambas as referências antecedem, porém, a publicação das obras de Rosa em língua polonesa. Portanto, no momento da circulação da notícia do falecimento do autor, o público leitor polonês não dispõe de nenhuma tradução de qualquer texto rosiano que lhe permita conferir a qualidade literária, alegada pela crítica, da obra de Rosa.

\section{A terceira margem}

A primeira tradução de um texto do autor em apreço para o polonês surge 18 meses mais tarde, isto é, logo no começo da época do chamado «boom latino-americano» na Polônia, cujo início costuma ser datado de 1968, o ano da publicação da tradução polonesa de Rayuela (1963), de Julio Cortázar. Seguindo provavelmente a ordem da publicação em França (cf. Faveri, 2009), o volume intitulado Soropita. Buriti (Rosa, 1969), que sai do prelo em junho de 1969, inclui as novelas Dão-Lalalão e Buriti (de Noites do sertão, editado originalmente em 1956), traduzidas por Helena Czajka (1902-1993) ${ }^{6}$. A publicação é noticiada nas listas de novidades literárias na edição de setembro de 1969 da revista Miesięcznik Literacki (Mensário Literário) e na edição de outubro de 1969 da revista Twórczość (Criação).

Foram identificadas três resenhas do livro. Em seu artigo publicado na edição de 21 de setembro de 1969 da Tygodnik Powszechny, Andrzej Türk começa por enumerar várias imagens relacionadas tipicamente com o Brasil rural (embora mencionando também, como contraponto, a arquitetura de Niemayer e as favelas cariocas) e depois de uma

\footnotetext{
${ }^{6}$ Nas décadas de 1950 a 1970, Czajka traduziu para o polonês, obras de José Mauro de Vasconcelos, Carolina Maria de Jesus, Gilberto Freyre, Álvaro Cunhal, Soeiro Pereira Gomes, José Cardoso Pires, Ernesto Sábato e José Maria Arguedas, entre outros.
} 
série muito extensa de quadros e figuras acrescenta apenas:

Não faço ideia como o senhor João Guimarães Rosa consegue transformar este amontoado de lugares-comuns pitorescos em literatura, mas é difícil duvidar que é exatamente o que ele faz: atrai-nos para uma rede de palavras, manda descobrir e acrescentar na memória cores e cheiros, polpas e sons, [até que se percebam] rugas e poros da vida, e nós comecemos a acreditar no significado de uma visão que íamos considerar um exemplo perfeito de kitsch. (p. 6)

A resenha, portanto, ainda que positiva, não contribui substancialmente para o entendimento da obra, a não ser pela percepção da existência de uma dimensão mais profunda, oculta dos enredos regionalistas rosianos. Enquadra-se, assim, na tendência culturalista na recepção de Rosa no exterior, identificada na Alemanha e na Itália por Mendes (2003).

Depois do texto de Türk, não há ecos críticos na imprensa por 10 meses, até junho do ano seguinte. A resenha de Barbara Sosień na edição de 28 de junho de 1970 da revista Życie Literackie (Vida Literária), intitulada «W ciepłych krajach» (literalmente: «Nos países quentes»), discorre sobre as obras do venezuelano Miguel Otero Silva, do italiano Goffredo Parise e de Guimarães Rosa, todas publicadas em 1969 pela mesma editora, Państwowy Instytut Wydawniczy (Instituto Editorial do
Estado). A parte concernente às novelas rosianas, intitulada «Amor, ciúme e palmeiras», contrasta visivelmente com o texto de Türk, constituindo exemplo de uma leitura atenta e aprofundada do texto. A autora começa por dizer que o livro é para quem gosta de «romance psicológico e exotismo» (p. 10). Sublinha a relação do enredo com a natureza local, explicando as peculiaridades do sertão enquanto espaço desconhecido ao leitor polonês, e considera os dois contos incluídos no volume «[um] hino à beleza e à pujança da terra brasileira». Chama a atenção para as dese crições «quase poéticas» da natureza do Brasil, considera, curiosamente, os contos cheios de um «lirismo ingênuo» de gaúchos (gentílico que a autora explica como «pastores») e até procura explicar a organização de uma fazenda brasileira referindo-se a uma tradicional propriedade rural polonesa, bem como aproximar a poética de Rosa, através da evocação das imagens da natureza no conto «Puszcza jodłowa» (1925), da criação do polonês Stefan Żeromski (1864-1925). Termina do seguinte modo:

A ficção de João Rosa não toca nos profundos problemas morais ou sociais, não procura generalizações filosóficas. É, pura e simplesmente, uma interessante ficção pertencente a um gênero que mistura histórias de amor com exotismo ([uma obra] exótica, pelo menos para nós, provavelmente por ser realista), e a sua forma é bastante tradicional. É uma ótima leitura 
para tardes de chuva. Transfere-nos para o hemisfério sul, aproxima-nos de um mundo conhecido a partir de reportagens e filmes. (p. 10)

As observações de Sosień são surpreendentes para quem conhece tanto a dimensão filosófica da obra rosiana, aqui não reconhecida, como a complexidade formal de seus textos - nesta resenha considerados «bastante tradicionais».

No mês seguinte, na edição de 31 de julho de 1970, Bożena Chcińska, na sua resenha na Nowe Ksiq̨żki, se debruça sobre o livro de Rosa e Casas muertas, do venezuelano Miguel Otero Silva (ambos, como se disse, publicados em polonês no mesmo ano e na mesma série editorial). A autora já prevê o boom, que naquela época está ainda no princípio, reparando nos planos de várias editoras viradas cada vez mais para a literatura latino-americana. Chcińska sublinha a dimensão regionalista da ficção rosiana e a importância do regionalismo na afirmação da independência política e cultural nos países da América Latina. Nota também que a diferença entre o povo que vive no sertão e o resto do país se deve à «trágica história do sistema dos conquistadores» (pp. 845-846). O que mais chama à sua atenção é o caráter «primitivo» do mundo representando nos contos em questão. A autora sublinha, como Sosień, a diferença entre Soropita, com uma tensão dramática muito evidente, e Buriti - mais épico, mais próximo do romance. No entanto, também nesta re- senha podemos encontrar uma frase curiosa para quem conhece o original rosiano: «Rosa é moderado no emprego de palavras, a sua linguagem é enxuta» (p. 846). O que se percebe, portanto, nas resenhas de Sosień e Chcińska é o fato de que ambas alegam a simplicidade da forma e da linguagem de Rosa - uma consideração que será retomada mais adiante.

Depois da publicação de Soropita. Buriti, em 1969, a presença de Rosa na Polônia é sustentada pela publicação, em 1971, na recém-inaugurada revista Literatura na Świecie ( $L i$ teratura no Mundo) - que depois se tornará um dos periódicos mais importantes para a abertura do sistema literário polonês, sendo responsável pela introdução de vários autores estrangeiros - , de uma tradução, feita também por Czajka, de um trecho de Grande sertão: Veredas, intitulado «Sąd» («Tribunal»). No entanto, o fragmento não é acompanhado por nenhuma nota sobre o autor ou a obra, nem sequer informação sobre a origem do texto enquanto parte de uma obra mais extensa. Em consequência, a tradução não deve ser devidamente apreendida sob a ótica da totalidade da obra ficcional de Rosa, nem sequer relacionada com a publicação anterior na Polônia ou com os próximos planos editoriais (uma vez que a versão integral de Grande sertão: Veredas será lançada já no ano seguinte, sendo de esperar que na época da publicação do trecho Czajka já estivesse trabalhando na obra). 
Em 1972, na revista Kontynenty (Continentes), orientada para explorações de novos espaços geográficos e culturais, é editada a tradução - também da autoria de Czajka - do conto «A terceira margem do rio» (Rosa, 1972a). Em dezembro do mesmo ano, sai do prelo a tradução integral (de Czajka) da obra-prima de Rosa, Grande sertão: Veredas (Rosa, 1972b). O lançamento é noticiado em fevereiro de 1973 na Nowe Ksiq̨żki, na parte dedicada às novidades editoriais (embora na seção «Literatura Portuguesa», p. 90). Também a revista Miesięcznik Literacki comunica, em abril de 1973, a publicação de Wielkie pustkowie (literalmente: Enorme espaço deserto) por «oao Guimaros [sic] Rosa». A Twórczość anuncia o fato só em junho de 1973, ou seja, seis meses depois do lançamento.

Foram identificadas, novamente, três resenhas do livro, mas devido ao acesso extremamente difícil a uma delas, apenas foi possível a consulta de duas. Na edição de 3 de junho de 1973 da revista Kultura (Cultura), Krzysztof Sielicki alega que «o romance do escritor brasileiro Joao [sic] Guimaraes [sic] Rosa ensina ao leitor europeu como descobrir, por baixo de uma camada de exotismo colorido, sentidos mais profundos do comportamento humano» (p. 9). O crítico enxerga no livro - que compara com Buriti e considera «excelente» - «uma parábola sobre os homens do sertão» (palavra que ele utiliza alternadamente com «estepe») e «uma metáfora de situações existenciais» que permitem conhecer «o homem de uma esfera cultural que nos é desconhecida» (p. 9). ${ }^{7}$

A resenha de Jadwiga Karbowska é publicada na revista Nowe Książki, na edição de 29 de junho de 1973, um número com uma evidente orientação ibérica e ibero-americana, com textos sobre Carlos Fuentes, Julio Cortázar, José Maria Arguedas, etc. A autora revela, desde o início, um conhecimento relativamente abrangente da literatura brasileira. $\mathrm{Na}$ primeira parte de seu texto descreve as secas e a consequente fome no sertão, baseando-se na obra de Euclides da Cunha (nunca publicada na Polônia, e por isso citada a partir da edição francesa). Menciona a produção literária da década de 30 enquanto reação ao modernismo dos anos 20 , referindo-se à obra de Raquel de Queiroz, José Lins do Rêgo, José Américo de Almeida e de Jorge Amado, mas também à MPB (que apresenta como «canção literária»). Chegando quase a dois terços de seu texto, a autora evoca o lançamento de Soropita. Buriti, em 1969, mas afirma que «depois da excepcional beleza daqueles dois [contos], este romance provoca decepção» (p. 14). Acrescenta ainda que «se em vez deste wes-

\footnotetext{
${ }^{7}$ No final da resenha, Sielicki comete ainda um lapso, revelando um elemento importante do enredo: «As pessoas naquele mundo mantêm sempre uma sensibilidade de criança. Conseguem pular por cima das categorias morais impostas pela cultura e enfrentam, de repente, uma qualidade antes desconhecida do ser humano. Estão absorvidas no ato de conhecer, mas de todas elas apenas Riobaldo conseguiu refletir sobre o conhecido. Ajudou-lhe uma grande tragédia - a morte do amigo-menina».
} 
tern ${ }^{8}$ brasileiro ou desta história no estilo de Janosik os leitores quiserem ver o sertão em toda sua excepcional beleza, por favor procurem aqueles dois contos» (p. 14). Nos últimos três parágrafos do seu texto, a resenhista sugere à editora responsável pela publicação das obras de Rosa que o próximo lançamento brasileiro seja O romance d'a pedra do reino e o príncipe do sangue do vai-e-volta, de Ariano Suassuna (já conhecido devido ao Auto da compadecida, encenado e publicado na Polônia).

Assim, praticamente termina o percurso póstumo de João Guimarães Rosa na Polônia: com poucas publicações e escassas apreciações críticas. O esquecimento imediato em que caiu a obra rosiana pode ser comprovado pela antologia, editada em 1976, intitulada Piętnaście opowiadań iberoamerykańskich (Quinze contos ibero-americanos), com textos de vários autores de língua espanhola e portuguesa, inclusive uma nova tradução de «A terceira margem do rio» - conto publicado, como já se disse, em 1972, na tradução de Czajka —, desta

\footnotetext{
${ }^{8}$ A comparação da obra com os westerns fez parte da recepção de Grande sertão: Veredas nos Estados Unidos (Armstrong, 1999: 120-121). Observe-se também como na mesma frase Karbowska procura aproximar a figura exótica do jagunço através da referência Juraj Jánošík (1688-1713), um bandoleiro dos Cárpatos, personagem da cultura popular checa, eslovaca e polonesa, em que se baseou uma importante série da televisão polonesa, intitulada Janosik, transmitida na época da publicação da resenha, em 1973.
}

vez feita por Janina Z. Klave (1921-2008) ${ }^{9}$. Na orelha do livro há uma breve notícia sobre os autores reunidos no volume:

\begin{abstract}
Quinze contos ibero-americanos é uma seleta de vários autores. Alguns, como Jorge Luis Borges, Alejo Carpentier, Julio Cortázar, já se gravaram na memória do leitor polonês, outros, como Griselda Gambaro, Elena Garro, Monteiro Lobato, apresentam-se pela primeira vez. (Kaniowa, 1976)
\end{abstract}

Parece que Guimarães Rosa não é mencionado porque não se encaixa em nenhuma das duas categorias: ainda que não seja um autor estreante no sistema literário polonês, não marcou a sua presença na consciência dos leitores. Fica, de certo modo, na terceira margem do rio.

\section{Um pacto}

Como, então, se pode entender o percurso da obra de Rosa na Polônia? Para responder a esta questão, será proveitoso referir ainda a última tradução da obra rosiana, publicada na antologia Opowiadania brazylijskie (Contos brasileiros; Klave, 1977), os contos «Bracia Dagobé» e «Przeznaczenie» («Os ir-

\footnotetext{
9 Janina Zofia Klave (também Klawe), que a partir de meados dos anos 70 vai-se tornando a figura principal para a introdução dos autores de língua portuguesa na Polônia, será responsável pela tradução de Machado de Assis, Aluísio Azevedo, Lima Barreto, Nélida Piñon, Rubem Fonseca, entre outros autores brasileiros, para além de vários escritores portugueses.
} 
mãos Dagobé» e «Fatalidade», ambos do volume Primeiras estórias, de 1962), traduzidos por Klave.

Na nota sobre o autor, Rosa é apresentado como «o mais proeminente escritor do período pós-guerra» e «criador de uma nova época na literatura brasileira» (Klave, 1977: 301). Sua grandeza, portanto, tem que ser reafirmada através de um peritexto, uma vez que não foi reconhecida pela crítica polonesa. No entanto, um elemento sublinhado por Klave, enquanto organizadora do volume, se revela ainda mais instigante. A tradutora nota que «as experiências [de Rosa] na área da linguagem levaram à criação de um novo gênero de ficção, no qual as palavras adquirem novo conteúdo e surgem muitos neologismos baseados no antigo idioma português». Como se percebe, portanto, em 1977, exatamente 10 anos depois da morte do escritor e das primeiras notícias na imprensa polonesa sobre o falecimento de «um excelente virtuose de linguagem» (Tygodnik Powszechny, 1967: 4), que encanta pela «riqueza da palavra» (Nowe Ksiq̨żki, 1967: 1548), volta uma questão totalmente ausente ao longo da década da recepção de Rosa na Polônia: a linguagem. Convém reiterar que Barbara Sosień, em sua resenha de Soropita. Buriti, diz sobre o livro que «a sua forma é bastante tradicional», e que Bożena Chcińska, em seu comentário sobre o mesmo livro, alega que «Rosa é moderado no emprego de palavras [e que] a sua linguagem é enxuta». As duas resenhas da tradução de
Grande sertão: Veredas, por sua vez, não fazem nenhuma referência à linguagem rosiana.

Procurando explicar esta situação, deve-se observar com mais atenção as circunstâncias da publicação e, enfim, o próprio texto da tradução. A editora que lança ambas as traduções, Państwowy Instytut Wydawniczy (PIW), responsável pelo enorme sucesso de vários autores da América Latina na Polônia, não cria séries especificamente orientadas para as literaturas latino-americanas, como, por exemplo, a importantíssima série de literatura ibero-americana da Wydawnictwo Literackie (Editora Literária) ${ }^{10}$, que nos anos 1971-1989 publica cerca de 126 títulos (Gaszyńska-Magiera, 2011: 74). Desse modo, em vez de realçar o exotismo e a alteridade dos autores que supostamente formam um todo, como no caso da WL, a PIW procura antes introduzir autores em ciclos já existentes, integrando-os dentro de um quadro mais amplo da literatura mundial. Neste caso, na série «Współczesna Proza Świata» («Ficção Contemporânea Mundial»), na qual são editadas as traduções de Rosa, lançam-se também obras de autores como Italo Calvino, Umberto Eco,

\footnotetext{
10 A história da série foi extensamente discutida por Jerzy Brzozowski na palestra plenária «A literatura portuguesa na série ibérica da editora Wydawnictwo Literackie», no âmbito do congresso $A$ Volta ao Mundo em 40 Anos: Encontros e Reencontros em Língua Portuguesa, realizado nos dias 12 e 13 de abril de 2018, no Instituto de Estudos Ibéricos e Ibero-Americanos da Universidade de Varsóvia.
} 
Vladimir Nabokov, Susan Sontag, John Updike, Kurt Vonnegut, J. Maxweel Coetzee e Günter Grass, entre outros.

O que se percebe, portanto, é uma orientação da PIW para um leitor mais experiente e exigente, que na literatura procura não apenas o prazer, mas também valores estéticos e reflexão (Gaszyńska-Magiera, 2011: 81). Por isso, sendo destinadas a um público supostamente mais sofisticado e independente, as duas traduções de Rosa aparecem quase sem peritextos (como prefácios, notas, posfácios, etc.). As únicas informações que acompanham as edições são pequenos textos (entre quatro e cinco frases) nas orelhas dos livros, informando sobre o sucesso internacional do autor e sobre o sertão enquanto um espaço desconhecido.

O fato ainda mais curioso é que nas duas edições faltam referências ao caráter inovador da linguagem de Rosa - não porque este seja evidente no texto polonês, mas muito pelo contrário. A inovação é precisamente o que falta na linguagem da tradução. Vejamos, a título de exemplo, a abertura de Grande sertão: Veredas:

Nonada. Tiros que o senhor ouviu foram de briga de homem não, Deus esteja. Alvejei mira em árvore, no quintal, no baixo do córrego. Por meu acerto. Todo dia isso faço, gosto; desde mal em minha mocidade. Daí, vieram me chamar. Causa dum bezerro: um bezerro branco, erroso, os olhos de nem ser — se viu —; e com máscara de cachorro. Me disseram; não quis avistar. Mesmo que, por defeito como nasceu, arrebitado de beiços, esse figurava rindo feito pessoa. Cara de gente, cara de cão: determinaram — era o demo. (Rosa, 1956: 9)

Compare-se o trecho com a versão de Helena Czajka:

Nie, nic takiego. Te strzały, co pan słyszał, to nie porachunki osobiste. Bóg świadkiem. Strzelałem do celu na drzewie, w ogrodzie nad strumieniem. Dla wprawy. Lubię to, co dzień ćwiczę, od wczesnej młodości. I przyszli mnie zawołać. Szło o cielaka: białe, pokraczne cielę, prawie że bez oczu; a z pyskiem jak u psa. Tak mówili, sam nie chciałem patrzeć. Od urodzenia miało odwinięte wargi i wyglądało jak śmiejący się człowiek. Ludzka morda czy psia, powiedzieli: diabeł. (Rosa, 1972: 7)

Convertido literalmente para o polonês, o fragmento se revela extremamente simples:

Não, não é nada. Aqueles tiros que o senhor ouviu não foi um ajuste de contas pessoal, tomo Deus por testemunha. Estava atirando num alvo na árvore, no quintal junto ao córrego. Para me adestrar. Gosto disso, todo dia pratico, desde a minha primeira mocidade. E vieram me chamar. Caso de um bezerro: um bezerro branco, esquisito, quase sem olhos, e com focinho como um cachorro. É assim que diziam, eu não queria olhar. Desde o nascimento 
tinha beiço desenrolado e parecia um homem rindo. Focinho de homem ou de cachorro, disseram: o diabo.

Considerando, na esteira dos formalistas russos, que a linguagem rosiana impede a automatização no emprego do idioma, a tradução polonesa constitui um exemplo de «desautomatização traída», na acepção de Carlos Alberto Gohn (2003), que na tradução de James L. Taylor e Harriet de Onis para a língua inglesa observa exemplos de «tradução empobrecedora» através da facilitação sintática e vocabular. Como avisa Benedito Nunes (1969):

Não se pode traduzir Guimarães Rosa como quem, traduzindo um texto de boa narração em prosa, tratasse tão só de reconstituir, no corpo de outra língua, a matéria narrada ou descrita. A simples reconstituição da narrativa não basta para assegurar a fidelidade na tradução de textos que, como os de Guimarães Rosa, são fundamentalmente poéticos. (p. 197)

O pesquisador acrescenta: «O tradutor, apegado à literalidade, abandonaria a tarefa antes mesmo de iniciá-la» (p. 198).

À vista disso, é possível afirmar que no processo da inserção de um autor internacionalmente reconhecido para o sistema literário polonês, um dos componentes mais valiosos de sua obra - a linguagem - sofreu eliminação. A editora responsável pelo lançamento não se refere, nos escassos peritextos, à existência de uma dimensão formal inovadora na obra de Rosa, impedindo também que a crítica, sem acesso ao original, reconheça essa criatividade. Dado que os únicos textos que mencionam a linguagem peculiar do autor (notas sobre o falecimento) são publicados ainda antes de qualquer tradução, este aspecto sofre obliteração devido à ausência de exemplos concretos disponíveis em língua polonesa. Uma vez que as obras são incluídas em uma série destinada aos leitores experientes e independentes e, portanto, não vêm acompanhadas por nenhum tipo de prefácio ou posfácio, um Rosa «mutilado», reduzido à narração com pequenas marcas da oralidade, não desperta o devido interesse.

Será a qualidade da tradução decorrente do fato de as traduções serem elaboradas depois da morte do autor, ou seja, sem a sua preciosa ajuda? É sabido que João Guimarães Rosa costumava supervisionar atentamente a publicação de seus livros no exterior, como prova a sua abundante correspondência somando 372 documentos identificados no Acervo João Guimarães Rosa, no Instituto de Estudos Brasileiros, por Iná Valéria Rodrigues Verlangieri (1993: 5-6) —, sobretudo com os tradutores para o alemão, Curt Meyer-Clason, entre 1958 e 1967 (editada em Rosa, 2003b), para o inglês, Harriet de Onís, entre 1958 e 1966 (parcialmente reunida em Verlangieri, 1993), para o italiano, Edoardo Bizzari, entre 1959 e 1967 (editada em Rosa, 2003a ), para 
o francês, Jean Jacques Villard, entre 1961 e 1967 (que aparentemente está sendo preparada para a publicação por Márcia Valéria Martinez de Aguiar; FAPESP, 2018), e os tradutores para o espanhol, Ángel Crespo e Pilar Gómez Bedate, entre 1964 e 1967. Com eles, o autor estabeleceu um «pacto de colaboração» (Hoisel, 2006: 88), com o objetivo de garantir a boa qualidade do texto. Uma vez que a sua presença na Polônia tem um caráter póstumo, parecerá justificado crer que a impossibilidade deste pacto é um dos fatores responsáveis pelo esquecimento da obra rosiana na Polônia atual. No entanto, como alega Armstrong (2001: 81), as meIhores traduções de Grande sertão: Veredas (a italiana, a holandesa e a segunda tradução francesa) foram escritas depois da morte do autor e, portanto, sem a sua colaboração.

\section{Considerações finais}

Em Leksykon Pisarzy Świata. XX wiek (Dicionário de Escritores do Mundo. Século XX), de 1993, elaborado pela equipe da revista Literatura na Świecie a fim de apresentar autores sem os quais «o mapa da literatura mundial não seria [...] suficientemente exato» (p. 3), há um verbete sobre João Guimarães Rosa da autoria de Elżbieta Milewska. No final de seu texto se lê:

O mais importante elemento inovador introduzido por Rosa na literatura brasileira é uma forma de expressão original, única, considerada pela crítica uma verdadeira revolução de linguagem. [...] Infelizmente, esta riqueza e originalidade do estilo, que constituem o valor mais importante do romance de Rosa, não estão representadas, de alguma forma, na tradução polonesa (1972), portanto deve-se constatar, com pena, que a obra brasileira mais importante do século XX ainda não foi descoberta na Polônia.

Como leitor da literatura brasileira no exterior, em face da história lúgubre da presença de Guimarães Rosa na Polônia, prefiro crer, como o narrador Riobaldo nas últimas frases de Grande sertão: Veredas, que cada final é sempre apenas uma «travessia» (Rosa, 1956: 594) e que «nonada», que está presente no encerramento e no começo do romance, é, na verdade, um início. Por isso, acho excitante viver nos tempos em que a grandeza de João Guimarães Rosa ainda está por descobrir.

\section{Bibliografia}

\section{Impressa}

Aguiar, M.V.M. (2011). Arquivos e historicização de uma tradução: A recepção de Guimarães Rosa na França dos anos 1960. Manuscrítica. 20: 40-64;

Aguiar, M.V.M. (2014). Sete novelas à procura de um tradutor: A aventura de Corpo de baile na França. Letras de Hoje. 49 (2): 172-179;

Armstrong, P. (1999). Third world literary fortunes: Brazilian culture and its international reception. Bucknell University Press. Lewisburg, London;

Armstrong, P. (2001). Guimarães Rosa in translation: Scrittore, editore, traduttore, traditore. Luso-Brazilian Review. 38 (1): 63-87; 
Borowski, G. (2012). O tłumaczach, ludożercach, krytykach i czytelnikach: Moje drzewko pomarańczowe José Mauro de Vasconcelosa. Em: J. Górnikiewicz, I. Piechnik e M. Świątkowska (orgs.). Le Petit Prince et les amis au pays des traductions: Études dédiées à Urszula Dąmbskas -Prokop. Księgarnia Akademicka. Kraków;

Borowski, G. (2016). Oszukać głód: O trudnościach w przekładzie estetyki niedostatku na przykładzie powieści Zwiędłe życie Graciliano Ramosa. Em: E. Kujawska-Lis e A.W. Ndiaye (orgs.). Komunikacja międzykulturowa w świetle współczesnej translatologii: Teoretyczne i praktyczne aspekty przekładu literackiego. Katedra Filologii Angielskiej UWM. Olsztyn;

Borowski, G. (2018). O obecności poezji brazylijskiej w Polsce: Carlos Drummond de Andrade. Postscriptum Polonistyczne. 1 (21): 139148;

Charchalis, W. (2012). Rynek wydawniczy literatury iberyjskiej po roku 1989. Em: M. Ganczar e P. Wilczek (orgs.). Rola tłumacza i przekładu w epoce wielokulturowości i globalizacji. Wydawnictwo Naukowe Śląsk. Katowice;

Chcińska, B. (1970). Joao Guimares Rosa. Nowe Ksiq̨żki. 14: 845-846;

Faveri, C.B. (2009). A tradução de Guimarães Rosa na França. Alea. 11 (2): 264-277;

Gaszyńska-Magiera, M. (2011). Recepcja przekładów literatury iberoamerykańskiej w Polsce w latach 1945-2005 z perspektywy komunikacji międzykulturowej. Wydawnictwo Uniwersytetu Jagiellońskiego. Kraków;

Gohn, C.A. (2003). A desautomatização traída? Grande sertão: Veredas em tradução inglesa. Em: L. Parreira Duarte et al. (orgs.). Veredas de Rosa II. PUC Minas. Belo Horizonte;

Hoisel, E. (2006). João Guimarães Rosa: Diálogo com os tradutores. Floema. 2 (3): 87-102;

Jeździkowski, J. (2010). Pilar do comunismo ou escritor exótico? A recepção dos romances de Jorge Amado na Polônia. TradTerm. 17: 127-156;
Kaczorowski, B. (org.). (2007). Literatura Świata: Encyklopedia PWN. Wydawnictwo Naukowe PWN. Warszawa;

Kaniowa, M. (org.) (1976). Piętnaście opowiadań iberoamerykańskch. Wydawnictwo Literackie. Kraków;

Karbowska, J. (1973). Ciepło, zimno, a kiedy gorąco? Nowe Książki. 12 (560): 13-15;

Klave, J. (org.) (1977). Opowiadania brazylijskie. (Trad. de J. Klave). Wydawnictwo Literackie. Kraków;

Książki nadesłane. (1969). Miesięcznik Literacki. 9 (37): s.p.;

Książki nadesłane. (1969). Twórczość. 10 (291): s.p.;

Książki nadesłane. (1973). Miesięcznik Literacki. 4 (80): s.p.;

Książki nadesłane. (1973). Tworczość. 6 (335): s.p.;

Leksykon pisarzy świata: XX wiek. (1993). Fundacja Literatura Światowa. Warszawa;

Martins, N.S. (2008). O léxico de Guimarães Rosa. Editora da USP. São Paulo;

Mendes, E.A.M. (2003). A recepção da obra de Guimarães Rosa na Alemanha e na Itália. Em: L.P. Duarte et al. (orgs.). Veredas de Rosa II. PUC Minas. Belo Horizonte;

Milewska, E. (1992). A literatura brasileira na Polônia. Em: E. Milewska, I. Rymwid-Mickiewicz e E. Skłodowska. La presencia de la literatura latinoamericana en Polonia/A presença da literatura latinoamericana na Polônia. CESLA. Varsóvia;

Notícia do falecimento de João Guimarães Rosa. (1967). Nowe Książki. 24 (426): 1548;

Notícia do falecimento de João Guimarães Rosa. (1967). Tygodnik Powszechny. 50 (985): 4;

Nunes, B. (1969). Guimarães Rosa e tradução. Em: O dorso do tigre: Ensaios. Perspectiva. São Paulo;

Przegląd nowości wydawniczych. (1973). Nowe Książki. 3 (551): 90; 
Rónai, P. (1965). L'œuvre de J. Guimarães Rosa. Caravelle. 4: 5-21;

Rosa, J.G. (1956). Grande sertão: Veredas. Livraria José Olympio. Rio de Janeiro;

Rosa, J.G. (1969). Soropita. Buriti. (Trad. de H. Czajka). Państwowy Instytut Wydawniczy. Warszawa;

Rosa, J.G. (1971). Sąd. (Trad. de H. Czajka). Literatura na Świecie. 8: 93-113;

Rosa, J.G. (1972a). Trzeci brzeg rzeki. (Trad. de H. Czajka). Kontynenty. 5: 57-58;

Rosa, J.G. (1972b). Wielkie pustkowie. (Trad. de H. Czajka). Państwowy Instytut Wydawniczy. Warszawa;

Rosa, J.G. (2003a). João Guimarães Rosa: Correspondência com seu tradutor italiano Edoardo

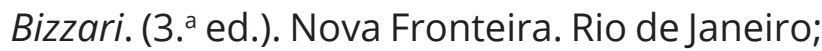
Rosa, J.G. (2003b). João Guimarães Rosa: Correspondência com seu tradutor alemão Curt Meyer-Clason (1968-1967). (Trad. de E.J. Paschoal). Nova Fronteira, Academia Brasileira de Letras, Editora da UFMG. Rio de Janeiro, Belo Horizonte, MG;

Sielicki, K. (1973). Ludzie z sertao. Kultura. 22 (521): 9;

Sosień, B. (1970). W ciepłych krajach. Życie Literackie. 26 (961): 10;

Türk, A. (1969). Joao Guimaraes Rosa: «Soropita. Buriti». Tygodnik Powszechny. 38 (1078): 6;

Verlangieri, I.V.R. (1993). J. Guimarães Rosa Correspondência inédita com a tradutora norte-americana Harriet de Onís: Parte I. Dissertação de Mestrado em Estudos Literários. Faculdade de Ciências e Letras da Universidade Estadual Paulista - Campus de Araraquara. 357 pp.;

\section{Digital}

FAPESP - Fundação de Amparo à Pesquisa do Estado de São Paulo. (2018). A correspondência entre João Guimarães Rosa e seu tradutor francês, Jean-Jacques Villard. Biblioteca virtual da FAPESP. Acedido em 20 de dezembro de 2018, em: https://bv.fapesp.br/pt/bolsas/139828/a-correspondencia-entre-joao-guimaraes-rosa-e-seu-tradutor-frances-jean-jacques-villard/;

João Guimarães Rosa. (s.d). Em: Wikipédia. Acedido em 20 de dezembro de 2018, em: https://pl.wikipedia.org/wiki/Jo\%C3\%A3o_Guimar\%C3\%A3es_Rosa;

Polska Bibliografia Literacka. (s.d.). Acedido em 20 de dezembro de 2018, em: http://pbl. ibl.poznan.pl/dostep;

Realizm magiczny (s.d). Em: Encyklopedia PWN. Acedido em 20 de dezembro de 2018, em: http://encyklopedia.pwn.pl/haslo/realizm-magiczny;3966446.html;

Wielkie pustkowie. (s.d.). Em: Lubimy czytać. Acedido em 20 de dezembro de 2018, em: http://lubimyczytac.pl/ksiazka/90524/wielkie-pustkowie;

Wielkie pustkowie. (s.d.). Em: Wikipédia. Aceє dido em 20 de dezembro de 2018, em: https:// pl.wikipedia.org/wiki/Wielkie_pustkowie. 